\title{
Parcelamento da adubação nitrogenada no desempenho produtivo de genótipos de trigo ${ }^{1}$
}

\author{
Splitting of nitrogen fertilization on the yield performance of wheat genotypes
}

\author{
Luciana Costa ${ }^{2 *}$, Claudemir Zucareli ${ }^{3}$ e Carlos Roberto Riede ${ }^{4}$
}

\begin{abstract}
RESUMO - Objetivou-se avaliar o desempenho produtivo de genótipos de trigo com diferentes qualidades industriais em resposta às proporções de parcelamento da adubação nitrogenada em cobertura. Foram avaliados seis genótipos de trigo, sendo estes: IPR 136 e LD 052114 (melhorador), IPR 130 e IPR 144 (pão) e BRS Louro e CD 105 (básico). A adubação nitrogenada em cobertura foi realizada na dose fixa de $80 \mathrm{~kg} \mathrm{ha}^{-1}$ na forma de ureia, com cinco formas de parcelamento como segue: P1- dose total aplicada no perfilhamento aos 20 DAE (dias após a emergência); P2 - 1/4 no emborrachamento e o restante aos 20 DAE; P3 - 1/2 aos 20 DAE + 1/2 no emborrachamento; P4 - 1/4 aos 20 DAE e o restante no emborrachamento e P5 - dose total de $\mathrm{N}$ aplicada no emborrachamento. As proporções de parcelamento da adubação nitrogenada em cobertura não afetaram o ciclo, o grau de acamamento, o peso hectolítrico (PH), a massa de 1.000 grãos, o número de espiguetas por espiga, o número de grãos por espigueta, o número de grãos por espiga, a massa de grãos por espiga e o ${ }^{\circ}$ de espiga $/ \mathrm{m}^{2}$. Os genótipos IPR 136 e LD 052114 apresentaram maiores rendimentos de grãos quando o $\mathrm{N}$ foi aplicado em uma única vez em P1 e P5, respectivamente. Para os genótipos BRS Louro, IPR 130 e CD 105 as diferentes épocas de adubação nitrogenada não afetaram a produtividade de grãos. Na cultivar IPR 144, a adubação nitrogenada em cobertura dos tratamentos P1, P2 e P5 favoreceu a produtividade de grãos.
\end{abstract}

Palavras-chave: Trigo. Cultivos de cobertura. Plantas. Efeito de Nitrogênio.

\begin{abstract}
This study aimed to evaluate the performance of wheat genotypes of different industrial qualities in response to the ratios of nitrogen $(\mathrm{N})$ fertilisation topdressing. Six genotypes of wheat were evaluated, those being: IPR LD 136 and 052114 (breeder), IPR 130 and IPR 144 (bread) and BRS Louro and CD 105 (basic). The nitrogen fertilisation topdressing was applied at a fixed dosage of $80 \mathrm{~kg} \mathrm{ha}^{-1}$ as urea, divided five ways: P1 - the total dosage being applied when tilling, at 20 DAE (days after emergence); P2 - 1/4 when booting and the remainder at 20 DAE; P3 $-1 / 2$ at $20 \mathrm{DAE}+1 / 2$ at booting; P4 - 1/4 at $20 \mathrm{DAE}$ and the remainder at booting; P5 - total $\mathrm{N}$ dosage applied at booting. The proportions for splitting the nitrogen fertilisation topdressing did not affect the cycle, the degree of bedding, the weight per hectolitre (HW), the 1000 grain mass, the number of spikelets per spike, the number of grains per spikelet, the number of grains per spike, the grain mass per spike and the number of spikes $/ \mathrm{m}^{2}$. The genotypes IPR 136 and 052 $114 \mathrm{LD}$ had higher grain yields when $\mathrm{N}$ was applied as a single application in P1 and P5 respectively. For the genotypes BRS Louro, IPR 130 and CD 105, the different nitrogen fertilization times did not affect grain yield. In cultivar IPR 144, the nitrogen fertilization topdressing in treatments P1, P2 and P5 favoured grain yield.
\end{abstract}

Key words: Wheat. Cover crops. Plants. Nitrogen effect.

\footnotetext{
* Autor para correspondência

${ }^{1}$ Recebido para publicação em 21/08/2011; aprovado em 09/08/2012

Parte da Dissertação do primeiro autor, bolsista CAPES

${ }^{2}$ Programa de Pós-Graduação em Agronomia, Departamento de Agronomia, Universidade Estadual de Londrina-UEL, Londrina-PR, Brasil, luciana.agrouel@yahoo.com.br

${ }^{3}$ Departamento de Agronomia, Universidade Estadual de Londrina /UEL, Londrina-PR, Brasil, claudemircca@uel.br

${ }^{4}$ Instituto Agronômico do Paraná/IAPAR, Londrina-PR, Brasil, crriede @iapar.br
} 


\section{INTRODUÇÃO}

O trigo (Triticum aestivum L.) é um dos cereais mais cultivados e importantes do mundo, representando aproximadamente $30 \%$ da produção mundial de grãos (OHLSON et al., 2010). É uma cultura de grande importância para o Brasil, havendo no país uma demanda crescente por derivados desse cereal, estimada em 10,4 milhões de toneladas para 2011 (COMPANHIA NACIONAL DE ABASTECIMENTO, 2011).

$\mathrm{Na}$ cultura do trigo a produtividade e a qualidade dos grãos são afetadas por diversos fatores, entre os quais se destaca o potencial genético da cultivar (TRINDADE et al., 2006), bem como a quantidade de nutrientes acumulados pela planta, que na maior parte são fornecidos pela adubação.

Segundo Scalco et al. (2002), a adubação nitrogenada faz-se necessária em virtude da quantidade insuficiente de nitrogênio $(\mathrm{N})$ que o solo fornece para o adequado crescimento e desenvolvimento das culturas, sendo necessário fornecer esse nutriente na forma de fertilizantes. Assim, esse nutriente é requerido em maior quantidade pelas plantas cultivadas (SOUZA; FERNANDES, 2006), participando de uma série de rotas metabólicas importantes na bioquímica das plantas (SANGOI et al., 2008).

A aplicação de $\mathrm{N}$ no momento adequado pode aumentar sua eficiência de uso pela cultura do trigo e alterar o rendimento de grãos por meio de estímulos aos componentes do rendimento (BREDEMEIER; MUNDSTOCK, 2001). Além dos aspectos agronômicos, a adubação na época apropriada reduz os processos de perdas do $\mathrm{N}$ por lixiviação, volatilização e desnitrificação.

$\mathrm{O} \mathrm{N}$ é o nutriente mais difícil de ser manejado nos solos de regiões tropicais e subtropicais, em virtude do grande número de reações e perdas a que está sujeito (ERNANI, 2003). Sendo assim, o parcelamento do adubo nitrogenado proporciona maior eficiência na absorção e, consequentemente, na assimilação do nutriente pela planta (MUNDSTOCK, 1999).

Segundo Rosa et al. (2005), para evitar perdas o melhor momento de aplicar o adubo nitrogenado é antes de uma precipitação pluvial de média intensidade, pois a dissolução e o transporte de nitrogênio para as raízes serão rápidos. Também, precipitações pluviais prolongadas ou de alta intensidade podem propiciar perdas de $\mathrm{N}$ por lixiviação ou por escoamento superficial.

Tradicionalmente, as culturas anuais recebem na semeadura apenas uma fração da dose total do $\mathrm{N}$ de que necessitam, enquanto que o restante é aplicado em cobertura, nas entrelinhas (TEIXEIRA FILHO et al., 2010), no estádio do perfilhamento.

A aplicação de $\mathrm{N}$ em cobertura no estádio de afilhamento dos cereais de inverno proporciona, em geral, incrementos significativos no rendimento de grãos (PERUZZO, 2000).

Já a aplicação tardia de $\mathrm{N}$ pode incrementar a sobrevivência dos afilhos emitidos pela planta e aumentar a massa dos grãos de trigo.

Acorssi e Ferreira (2009), investigando o comportamento da cultivar de trigo CD 104, com aplicação de $\mathrm{N}$ realizada antes do perfilhamento nas doses $0 ; 30 ; 60 ; 90$ e $120 \mathrm{~kg} \mathrm{ha}^{-1}$ de $\mathrm{N}$, verificaram que a adubação nitrogenada promoveu maior rendimento de grãos e número de grãos por espiga, porém não houve efeito significativo na massa de 1.000 grãos e no peso hectolítrico $(\mathrm{PH})$.

Anualmente no Brasil novas cultivares de trigo com maior potencial produtivo têm sido desenvolvidas e recomendadas pelos programas de melhoramento genético. Considerando que os genótipos respondem de maneira diferenciada à aplicação de $\mathrm{N}$ e que a fertilização nitrogenada pode proporcionar alterações nos componentes de produção e no rendimento da cultura do trigo, faz-se necessária a avaliação do comportamento dessas cultivares e linhagens de trigo em resposta à adubação nitrogenada em cobertura. Assim, objetivou-se avaliar o desempenho produtivo de genótipos de trigo com diferentes qualidades industriais em resposta às proporções de parcelamento da adubação nitrogenada em cobertura.

\section{MATERIAL E MÉTODOS}

O trabalho foi realizado no município de Londrina-PR, em Latossolo Vermelho distroférrico localizado nas seguintes coordenadas geográficas: latitude $23^{\circ} 22^{\prime} \mathrm{S}$, longitude $50^{\circ} 11^{\prime} \mathrm{W}$ e altitude $585 \mathrm{~m}$ (TAZIMA et al. 2008). O clima da região é do tipo Cfa, descrito como clima subtropical úmido com verão quente, segundo classificação de Köpen. As temperaturas médias, máxima e mínima, são 27,3 e $16,0{ }^{\circ} \mathrm{C}$, respectivamente e a precipitação média anual é de $1.588 \mathrm{~mm}$ (CAVIGLIONE et al., 2000). Os dados de precipitação pluvial e de temperatura relativos ao período de condução do experimento, obtidos junto à Estação Meteorológica do IAPAR em Londrina-PR, estão apresentados nas Figuras 1.

Foram avaliados seis genótipos de trigo com diferentes qualidades industriais, sendo estes IPR 136 e LD 052114 (melhorador), IPR 130 e IPR 144 (pão) e BRS LOURO e CD 105 (básico). Os genótipos IPR 
Figura 1 - Dados médios por decêndio de temperatura e precipitação pluvial para o período de condução do experimento em Londrina-PR, para o ano de 2009

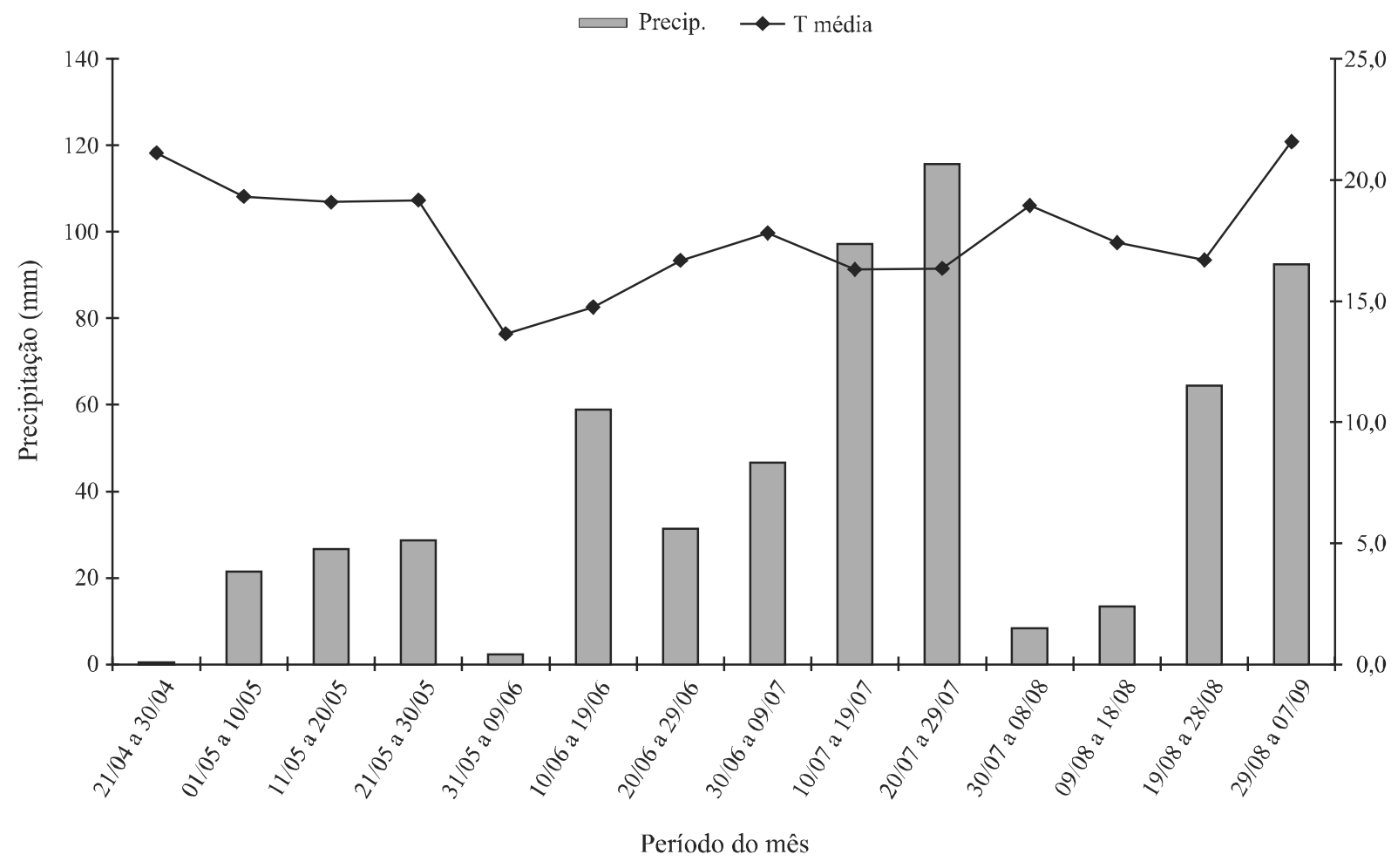

136 e LD 052114 possuem ciclo médio e mostram resistência moderada ao acamamento. Pertencem à classe industrial de trigo melhorador, que envolve os grãos de genótipos aptos para mesclas com farinhas mais fracas, visando aumentar a qualidade geral da massa e produção de pães industriais.

Os genótipos IPR 130 e IPR 144 pertencem à classe industrial tipo pão, apropriada à produção de pães do tipo francês. Esses genótipos têm ampla adaptação, podendo ser cultivados nos estados do Paraná, Mato Grosso do Sul e São Paulo. São moderadamente resistentes ao acamamento e à debulha natural, e moderadamente susceptíveis à germinação pré-colheita.

Já os genótipos BRS Louro e CD 105 são enquadrados como trigo básico, apropriado para a produção de biscoitos, bolachas e pizzas. Possuem resistência moderada ao acamamento e são moderadamente tolerantes ao crestamento.

O delineamento experimental foi de blocos ao acaso, com parcelas subdivididas, em esquema fatorial 6x5, com quatro repetições. As parcelas corresponderam a seis genótipos de trigo e as sub-parcelas às cinco diferentes proporções de parcelamento da dose de $\mathrm{N}$ aplicada em cobertura.
Foi realizada adubação nitrogenada em cobertura com dose fixa de $80 \mathrm{~kg} \mathrm{ha}^{-1}$ (FRONZA; CAMPOS; RIEDE, 2008) na forma de ureia $(45 \% \mathrm{~N})$, aplicandose cinco formas de parcelamento como segue: P1- dose total aplicada no perfilhamento aos 20 DAE (dias após a emergência); P2- 1/4 no emborrachamento e o restante aos 20 DAE; P3- $1 / 2$ aos 20 DAE e a outra $1 / 2$ no emborrachamento; P4- $1 / 4$ aos 20 DAE e o restante no emborrachamento e P5- dose total de $\mathrm{N}$ aplicada no emborrachamento.

As características químicas do solo na profundidade de 0 a $20 \mathrm{~cm}$, determinadas antes da instalação do experimento, foram representadas por: $\mathrm{pH}\left(\mathrm{CaCl}_{2}\right.$ 0,01 mol L-1 4,$9 ; 6,2 \mathrm{cmol}_{\mathrm{c}} \mathrm{dm}^{-3} \mathrm{de} \mathrm{H}^{+}+$

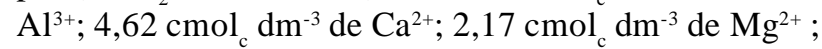
$0,27 \mathrm{cmol}_{\mathrm{c}} \mathrm{dm}^{-3} \mathrm{de} \mathrm{K}^{+} ; 5,2 \mathrm{mg} \mathrm{dm}^{-3}$ de P; $59,20 \mathrm{~g} \mathrm{dm}^{-3} \mathrm{de}$ matéria orgânica e 53,24\% de saturação de bases.

O experimento foi conduzido sob sistema plantio convencional em área anteriormente ocupada com a cultura da soja. Com base nas características químicas do solo da área experimental, calculou-se a adubação mineral básica no sulco de semeadura, constante para todos os tratamentos, que foi de $30 \mathrm{~kg} \mathrm{ha}^{-1}$ de $\mathrm{N}, 60 \mathrm{~kg} \mathrm{ha}^{-1}$ de $\mathrm{P}_{2} \mathrm{O}_{5}$ e $60 \mathrm{~kg} \mathrm{ha}^{-1} \mathrm{de}_{2} \mathrm{O}$ utilizando-se a fórmula 10-20-20. 
Os genótipos de trigo foram semeados mecanicamente no dia 30 de abril de 2009, a três centímetros de profundidade e com densidade de 350 sementes $\mathrm{m}^{-2}$. A dimensão das subparcelas experimentais foi de seis linhas de cinco metros de comprimento espaçadas $17 \mathrm{~cm}$, descartando-se a linha das extremidades. O espaçamento foi de um metro entre parcelas e de dois metros entre blocos.

Foram realizadas as seguintes avaliações: a) ciclo ao espigamento: expresso em número de dias desde a emergência das plântulas até o espigamento quando cerca de $50 \%$ das espigas estavam saindo da bainha; b) altura de plantas: Foi definida como sendo a distância $(\mathrm{cm})$ do nível do solo ao ápice das espigas, excluindo-se as aristas, medindo-se cinco plantas ao acaso e representativas da área útil de cada parcela; c) grau de acamamento: obtido por meio de observações visuais, na fase de maturação da planta, utilizando-se a escala de notas de 0 a 10 , sendo que a nota 10 representa $100 \%$ das plantas e 0 refere-se a nenhuma planta da parcela acamada; d) número de espigas por metro quadrado: na ocasião da colheita, foi determinado por meio de contagem, o número de espigas em 1,0 m de fileira de plantas na área útil das parcelas, em seguida, foi calculado o número de espigas por $\mathrm{m}^{2}$, mediante a multiplicação do número de espigas por metro pelo espaçamento entre-linhas de plantas $(0,17 \mathrm{~m})$.

A colheita das plantas foi realizada após os grãos atingirem a maturação de colheita (estádio fenológico 11.4, escala de Feekes). Após a maturação da cultura, foram colhidas 10 espigas de trigo ao acaso em cada parcela, para a determinação das quatro características a seguir: e) número de espiguetas por espiga: determinada a partir da contagem de todas as espiguetas com grãos da espiga; f) número de grãos por espigueta: determinado a partir da divisão do número de grãos por espiga pelo número de espiguetas por espiga; g) número de grãos por espiga: obtido a partir da contagem do número de grãos por espiga; h) massa de grãos por espiga: determinado a partir da massa total dos grãos de cada espiga; i) peso hectolítrico: determinado em balança de $0,25 \mathrm{~L}$, com teor de água dos grãos corrigidos para $13 \%$ (base úmida); j) massa de 1.000 grãos: obtida mediante a contagem e pesagem de oito repetições de 100 grãos de trigo. A média desses valores foi multiplicada por 10 para obtenção do valor da massa de 1.000 grãos; k) produtividade de grãos: determinada pela coleta das plantas contidas nas quatro linhas centrais de cada parcela, sendo o comprimento da linha igual a $5,0 \mathrm{~m}$. Após a trilhagem mecânica, os grãos foram pesados e os dados transformados em $\mathrm{kg} \mathrm{ha}^{-1}$ a $13 \%$ de umidade.

A análise de variância foi conduzida aplicando-se o teste de F, com comparação de médias realizada pelo teste de Scott Knott, a 5\%. As análises foram realizadas com auxílio do programa computacional SISVAR.

\section{RESULTADOS E DISCUSSÃO}

Houve interação significativa entre os genótipos e as proporções de parcelamento da adubação nitrogenada de cobertura para a característica altura de plantas. Para o ciclo até o espigamento e grau de acamamento de plantas observou-se efeito isolado de genótipos (Tabela 1 e 2).

Os genótipos BRS Louro e CD 105, que apresentaram o atributo ciclo ao espigamento significativamente menor em relação aos demais, são classificados como trigo de ciclo precoce.

O acamamento é um dos fatores que mais limita a maximização da produção de grãos de trigo. Quanto a esta variável, a linhagem LD 052114 proporcionou os menores valores, diferindo significativamente dos demais genótipos. Já os genótipos IPR 144, IPR 130 e IPR 136 apresentaram maiores índices de acamamento. O grau de suscetibilidade de diferentes genótipos é variável, sendo encontrada resistência em genótipos extremamente distintos quanto aos demais caracteres de interesse dos melhoristas.

Cabe ressaltar que as condições climáticas durante a fase final do experimento não foram adequadas à cultura do trigo. Uma intensa chuva e ventos fortes durante o florescimento de grãos provocou o acamamento no trigo, o que segundo Silva et al. (2006), pode interromper o movimento dos fotoassimilados, resultando em prejuízo, sobretudo no peso dos grãos.

As diferentes proporções de parcelamento da adubação nitrogenada em cobertura não afetaram a altura de plantas dos genótipos CD 105, IPR 130 e LD 052114. Para o genótipo IPR 136 as menores alturas de plantas foram observadas quando o $\mathrm{N}$ em cobertura foi aplicado de forma parcelada, em comparação a uma única aplicação. Já para o IPR 144 a maior altura foi obtida com aplicação de $\mathrm{N}$ em P3 (Tabela 3), possivelmente porque o parcelamento da dose da adubação nitrogenada ( $1 / 2$ no perfilhamento e $1 / 2$ no emborrachamento) otimizou a eficiência do $\mathrm{N}$ pelo genótipo e reduziu perdas por lixiviação ou volatilização.

Para as formas de parcelamento P1 e P4 as maiores alturas de plantas foram verificadas para os genótipos CD 105, IPR 144 e LD 052114. Em P2 os genótipos CD 105 e IPR 144 obtiveram alturas superiores. Estes são classificados como genótipos de porte médio (BASSOI et al., 2010; CUNHA et al., 2004) e possuem altura média 
Tabela 1 - Ciclo ao espigamento (CI), altura de plantas (ALT) e grau de acamamento (AC), em função dos genótipos e proporções de parcelamento da adubação nitrogenada em cobertura na cultura do trigo, Londrina-PR, 2009

\begin{tabular}{llll}
\hline \multicolumn{1}{c}{ Tratamentos } & CI & ALT & AC \\
\hline Parcelamento (P) & (dias) & $(\mathrm{cm})$ & 3,62 \\
\hline P1 & 66,54 & 93,26 & 3,54 \\
P2 & 66,08 & 91,52 & 3,58 \\
P3 & 66,37 & 93,33 & 3,2 \\
P4 & 66,45 & 92,20 & 3,08 \\
P5 & 66,41 & 92,73 & \\
Genótipos (G) & & & $3,10 \mathrm{~b}$ \\
BRS Louro & $63,45 \mathrm{~b}$ & 91,55 & $2,00 \mathrm{~b}$ \\
CD 105 & $62,05 \mathrm{~b}$ & 95,91 & $4,75 \mathrm{a}$ \\
IPR 144 & $66,10 \mathrm{a}$ & 96,95 & $4,60 \mathrm{a}$ \\
IPR 130 & $67,70 \mathrm{a}$ & 92,08 & $5,85 \mathrm{a}$ \\
IPR 136 & $68,35 \mathrm{a}$ & 84,00 & $0,15 \mathrm{c}$ \\
LD 052114 & $70,60 \mathrm{a}$ & 95,18 & \\
\hline
\end{tabular}

1 - lamento (P) mento e Grãos s médias seguidas de letras diferentes são estatisticamente distintas entre si de acordo com o teste de Scott Knott, a de 5\%. P1 - dose total de $\mathrm{N}\left(80 \mathrm{Kg} \mathrm{ha}^{-1}\right)$ aplicada aos 20 DAE (dias após a emergência); P2 - 1/4 no emborrachamento e o restante aos 20 DAE; P3 - 1/2 aos 20 DAE + 1/2 no emborrachamento; P4 - 1/4 aos 20 DAE e o restante no emborrachamento e P5 - dose total de N aplicada no emborrachamento

Tabela 2 - Quadrados médios obtidos por análise de variância em parcelas sub-divididas para as variáveis ciclo ao espigamento (CI), altura de plantas (ALT) e grau de acamamento (AC), em função dos genótipos e proporções de parcelamento da adubação nitrogenada em cobertura na cultura do trigo, Londrina-PR, 2009

\begin{tabular}{lccc}
\hline \multicolumn{1}{c}{ F.V. } & CI & ALT & AC \\
\hline Quadrados médios & & & \\
Bloco & $14,63^{\text {ns }}$ & $11,95^{\text {ns }}$ & $9,91^{\text {ns }}$ \\
Genótipos (G) & $203,37^{* *}$ & $447,69^{* *}$ & $87,50^{* *}$ \\
Erro (a) & 19,18 & 14,13 & 3,76 \\
Parcelamento (P) & $0,72^{\text {ns }}$ & $13,79^{*}$ & $1,44^{\text {ns }}$ \\
PxG & $0,42^{\text {ns }}$ & $8,81^{*}$ & $1,12^{\text {ns }}$ \\
Resíduo & 0,86 & 4,16 & 1,56 \\
CV (\%) parcela & 6,60 & 4,06 & 56,94 \\
CV (\%) sub-parcela & 1,40 & 2,20 & 36,76 \\
\hline
\end{tabular}

ns - não significativo a $5 \% ; *$ - significativo a $5 \% ; * *$ - significativo a $1 \%$ 
Tabela 3 - Altura de plantas e as proporções de parcelamento da adubação nitrogenada em cobertura para altura de plantas (cm), Londrina-PR, 2009

\begin{tabular}{lcccccc}
\hline & \multicolumn{7}{c}{ Genótipos } \\
\cline { 2 - 7 } & BRS LOURO & CD 105 & IPR 144 & IPR 130 & IPR 136 & LD 052114 \\
\hline P1 & $92,5 \mathrm{bA}$ & $98,3 \mathrm{aA}$ & $96,2 \mathrm{aB}$ & $91,7 \mathrm{bA}$ & $85,00 \mathrm{cA}$ & $95,7 \mathrm{aA}$ \\
P2 & $91,2 \mathrm{bB}$ & $95,0 \mathrm{aA}$ & $97,0 \mathrm{aB}$ & $92,0 \mathrm{bA}$ & $81,25 \mathrm{cB}$ & $92,6 \mathrm{bA}$ \\
P3 & $93,7 \mathrm{cA}$ & $95,0 \mathrm{bA}$ & $100,0 \mathrm{aA}$ & $91,6 \mathrm{cA}$ & $83,33 \mathrm{~dB}$ & $96,2 \mathrm{bA}$ \\
P4 & $90,0 \mathrm{bB}$ & $96,2 \mathrm{aA}$ & $96,2 \mathrm{aB}$ & $92,0 \mathrm{bA}$ & $83,75 \mathrm{cB}$ & $95,0 \mathrm{aA}$ \\
P5 & $90,2 \mathrm{bB}$ & $95,0 \mathrm{aA}$ & $95,2 \mathrm{aB}$ & $93,0 \mathrm{aA}$ & $86,66 \mathrm{cA}$ & $96,2 \mathrm{aA}$ \\
\hline
\end{tabular}

Letras iguais minúsculas na linha e maiúsculas na coluna não diferem entre si pelo teste de Scott Knott a 5\%. P - parcelamento da adubação nitrogenada. P1 - dose total de N (80 kg ha $\left.{ }^{-1}\right)$ aplicada aos 20 DAE (dias após a emergência); P2 - 1/4 no emborrachamento e o restante aos 20 DAE; P3 - 1/2 aos 20 DAE + 1/2 no emborrachamento; P4 - 1/4 aos 20 DAE e o restante no emborrachamento e P5 - dose total de N aplicada no emborrachamento

Tabela 4 - Peso hectolítrico (PH), massa de 1000 grãos (MMG), número de espiguetas/espiga (ET/E), número de grãos/espigueta (G/ET), número de grãos/espiga (G/E), massa de grão/espiga (MG/E), espiga/m² (E/M²), produtividade de grãos (PR), em função dos genótipos e proporções de parcelamento da adubação nitrogenada em cobertura. Londrina-PR, 2009

\begin{tabular}{llllllllr}
\hline \multicolumn{1}{c}{ Tratamentos } & PH & MMG & ET/E & G/ET & G/E & MG/E & E/M & PR \\
\hline Parcelamento $(\mathrm{P})$ & $\left(\mathrm{kg} \mathrm{hl}^{-1}\right)$ & $(\mathrm{g})$ & & & & $(\mathrm{g})$ & & $\left(\mathrm{kg} \mathrm{h}^{-1}\right)$ \\
\hline P1 & 69,61 & 27,88 & 15,29 & 2,12 & 32,59 & 0,86 & 486,76 & 1202,49 \\
P2 & 69,7 & 27,91 & 15,37 & 2,14 & 33,12 & 0,88 & 486,02 & 1216,17 \\
P3 & 69,48 & 27,69 & 15,14 & 2,12 & 32,24 & 0,85 & 487,74 & 1015,71 \\
P4 & 69,75 & 27,58 & 15,35 & 2,05 & 31,61 & 0,84 & 469,36 & 1127,35 \\
P5 & 70,15 & 27,59 & 14,94 & 2,15 & 32,13 & 0,85 & 461,51 & 1189,99 \\
Genótipos & & & & & & & & \\
BRS Louro & $72,35 \mathrm{a}$ & $26,57 \mathrm{c}$ & $15,51 \mathrm{~b}$ & $2,22 \mathrm{a}$ & 34,72 & 0,94 & 544,11 & 1443,15 \\
CD 105 & $66,64 \mathrm{~b}$ & $27,58 \mathrm{~b}$ & $16,24 \mathrm{a}$ & $2,00 \mathrm{~b}$ & 32,8 & 0,81 & 456,47 & 1102,40 \\
IPR 144 & $71,05 \mathrm{a}$ & $30,86 \mathrm{a}$ & $16,38 \mathrm{a}$ & $1,98 \mathrm{~b}$ & 32,66 & 0,98 & 588,42 & 1523,29 \\
IPR 130 & $69,71 \mathrm{a}$ & $28,15 \mathrm{~b}$ & $15,68 \mathrm{~b}$ & $1,96 \mathrm{~b}$ & 31,2 & 0,8 & 476,47 & 895,63 \\
IPR 136 & $70,20 \mathrm{a}$ & $27,49 \mathrm{~b}$ & $13,26 \mathrm{~d}$ & $2,34 \mathrm{a}$ & 31,25 & 0,94 & 472,94 & 1069,84 \\
LD 052114 & $68,48 \mathrm{~b}$ & $25,75 \mathrm{c}$ & $14,24 \mathrm{c}$ & $2,19 \mathrm{a}$ & 31,41 & 0,73 & 410,88 & 879,52 \\
\hline
\end{tabular}

As médias seguidas de letras diferentes são estatisticamente distintas entre si de acordo com o teste de Scott Knott, a de 5\%. P1 - dose total de $\mathrm{N}\left(80 \mathrm{~kg} \mathrm{ha}^{-1}\right)$ aplicada aos 20 DAE (dias após a emergência); P2 - 1/4 no emborrachamento e o restante aos 20 DAE; P3 - 11/2 aos 20 DAE + 1/2 no emborrachamento; P4 - 1/4 aos 20 DAE e o restante no emborrachamento e P5 - dose total de $\mathrm{N}$ aplicada no emborrachamento

de plantas entre 83 e $89 \mathrm{~cm}$ (OSÓRIO, 1992). Em todas as formas de parcelamento de $\mathrm{N}$ a cultivar IPR 136 apresentou menor altura em comparação aos demais genótipos, sendo classificada como cultivar de porte baixo com altura de planta média de $80 \mathrm{~cm}$ (BASSOI et al., 2010).

Verificou-se efeito significativo apenas de genótipos para as variáveis peso hectolítrico, massa de 1.000 grãos, espigueta por espiga e grãos por espigueta (Tabela 4 e 5). Houve efeito de interação entre os fatores estudados para a produtividade de grãos (Tabela 6).
Os genótipos LD 052114 e CD 105 apresentaram médias significativamente inferiores de peso hectolítrico (PH) em relação aos demais genótipos, com 68,4 e $66,64 \mathrm{~kg} \mathrm{hl}^{-1}$, respectivamente (Tabela 4). O PH é utilizado como medida tradicional de comercialização em vários países e expressa indiretamente a qualidade de grãos. Sabe-se que quanto maior o $\mathrm{PH}$, maior o valor comercial do produto. Os valores de $\mathrm{PH}$ obtidos neste estudo estão abaixo das classificações de tipos de grãos destinados à moagem $(\mathrm{PH}>72)$ e apresentam, 
Tabela 5 - Quadrados médios obtidos por análise de variância em parcelas sub-divididas para as variáveis peso hectolítrico (PH), massa de 1000 grãos (MMG), número de espiguetas/espiga (ET/E), número de grãos/espigueta (G/ET), número de grãos/espiga (G/E), massa de grão/espiga (MG/E), espiga/m² (E/M²), produtividade de grãos (PR), em função dos genótipos e proporções de parcelamento da adubação nitrogenada em cobertura. Londrina-PR, 2009

\begin{tabular}{lcccccccc}
\hline \multirow{2}{*}{ F.V. } & PH & MMG & ET/E & G/ET & G/E & MG/E & E/M & PR \\
\cline { 2 - 9 } & \multicolumn{7}{c}{ Quadrados médios } \\
\hline Bloco & $36,53^{\text {ns }}$ & $8,18^{\text {ns }}$ & $0,27^{\text {ns }}$ & $0,17^{\text {ns }}$ & $44,95^{\text {ns }}$ & $0,21^{\text {ns }}$ & $17574,31^{\text {ns }}$ & $10931991,71^{* *}$ \\
Genótipo (G) & $79,89^{* *}$ & $61,22^{* *}$ & $29,93^{* *}$ & $0,49^{\text {ns }}$ & $37,36^{\text {ns }}$ & $0,17^{\text {ns }}$ & $41269,40^{\text {ns }}$ & $1487523,19^{* *}$ \\
Erro (a) & 15,89 & 3,53 & 0,38 & 0,05 & 20,84 & 0,07 & 20792,82 & 138679,83 \\
Parcelamento (P) & $1,54^{\text {ns }}$ & $0,57^{\text {ns }}$ & $0,76^{\text {ns }}$ & $0,03^{\text {ns }}$ & $7,52^{\text {ns }}$ & $0,004^{\text {ns }}$ & $3492,38^{\text {ns }}$ & $168848,81^{\text {ns }}$ \\
PxG & $5,19^{\text {ns }}$ & $2,97^{\text {ns }}$ & $0,50^{\text {ns }}$ & $0,04^{\text {ns }}$ & $16,43^{\text {ns }}$ & $0,04^{\text {ns }}$ & $2040,98^{\text {ns }}$ & $393580,89^{* *}$ \\
Resíduo & 3,90 & 2,52 & 0,55 & 0,03 & 12,1 & 0,02 & 1890,33 & 182647,35 \\
CV (\%) parcela & 5,72 & 6,78 & 4,06 & 11,28 & 14,12 & 32,42 & 30,15 & 32,32 \\
CV (\%) sub-parcela & 2,83 & 5,73 & 4,90 & 8,40 & 10,76 & 17,67 & 9,09 & 37,09 \\
\hline
\end{tabular}

ns - não significativo a $5 \% ; *$ - significativo a $5 \% ; * *$ - significativo a $1 \%$

Tabela 6 - Desdobramento da interação genótipos e proporções de parcelamento da adubação nitrogenada em cobertura para produtividade de grãos $\left(\mathrm{kg} \mathrm{ha}^{-1}\right)$. Londrina-PR, 2009

\begin{tabular}{lrrrrrr}
\hline & \multicolumn{7}{c}{ Genótipos } \\
\cline { 2 - 7 } & BRS Louro & \multicolumn{1}{c}{ CD 105 } & \multicolumn{1}{c}{ IPR 144 } & \multicolumn{1}{c}{ IPR 130 } & IPR 136 & LD 052114 \\
\hline P1 & $1218,73 \mathrm{aA}$ & $1313,20 \mathrm{aA}$ & $1694,10 \mathrm{aA}$ & $748,80 \mathrm{bA}$ & $1631,53 \mathrm{aA}$ & $608,58 \mathrm{bB}$ \\
P2 & $1541,87 \mathrm{aA}$ & $1197,66 \mathrm{bA}$ & $1830,67 \mathrm{aA}$ & $1171,27 \mathrm{bA}$ & $972,28 \mathrm{bB}$ & $577,31 \mathrm{bB}$ \\
P3 & $1474,61 \mathrm{aA}$ & $867,80 \mathrm{aA}$ & $1190,26 \mathrm{aB}$ & $916,75 \mathrm{aA}$ & $1019,80 \mathrm{aB}$ & $624,99 \mathrm{aB}$ \\
P4 & $1549,49 \mathrm{aA}$ & $953,66 \mathrm{aA}$ & $1166,51 \mathrm{aB}$ & $1048,34 \mathrm{aA}$ & $1083,17 \mathrm{aB}$ & $953,66 \mathrm{aB}$ \\
P5 & $1430,97 \mathrm{aA}$ & $1179,66 \mathrm{aA}$ & $1735,41 \mathrm{aA}$ & $587,04 \mathrm{bA}$ & $642,42 \mathrm{bB}$ & $1623,82 \mathrm{aA}$ \\
\hline
\end{tabular}

Letras iguais minúsculas na linha e maiúsculas na coluna não diferem entre si pelo teste de Scott Knott a 5\%. P - parcelamento da adubação nitrogenada. P1 - dose total de N (80 kg ha ${ }^{-1}$ ) aplicada aos 20 DAE (dias após a emergência); P2 - 1/4 no emborrachamento e o restante aos 20 DAE; P3 - 1/2 aos 20 DAE + 1/2 no emborrachamento; P4 - 1/4 aos 20 DAE e o restante no emborrachamento e P5 - dose total de N aplicada no emborrachamento

portanto, baixo valor comercial, pois na prática o valor recebido pelo produtor rural é menor quando a massa hectolítrica se apresenta abaixo de $78 \mathrm{~kg} \mathrm{hl}^{-1}$ (MEGDA et al., 2009). Esse resultado provavelmente se deve a interferência das condições climáticas durante o ciclo da cultura, particularmente o regime de chuvas (Figura 1) que favoreceu o aparecimento de doenças, o acamamento e a germinação pré-colheita. Essa última é apontada como a principal causa da redução das características qualitativas e quantitativas de trigo.

Os valores inferiores de $\mathrm{PH}$ encontrados para a CD 105 e LD 052114 podem também estar relacionados à maior incidência de brusone (Pyricularia grisea) nestes genótipos, conforme foi observado no experimento de campo. De acordo com Goulart (2004) e Goulart et al.
(2007), esta doença da parte aérea pode causar perdas em peso por espiga de até $74 \%$, dependendo da época da infecção.

Valores muito baixos de $\mathrm{PH}$ podem indicar ocorrência de problemas na lavoura que podem ter afetado o enchimento dos grãos e sua qualidade (GUARIENTI, 1996). Chuvas no período inicial da maturação afetam, principalmente, características quantitativas (massa de mil grãos, $\mathrm{PH}$ e rendimento de farinha) (FRANCESCHI et al., 2009).

As proporções de parcelamento da adubação nitrogenada não influenciaram a massa de grãos. Resultados semelhantes foram obtidos por Nakagawa, Cavaniani e Machado (2000) avaliando efeito da 
adubação nitrogenada em cobertura sobre a produção e a qualidade de aveia-preta. Estes autores constataram que o peso hectolítrico e a massa de 1.000 grãos não foram significativamente afetados pelas doses de $\mathrm{N}$ testadas $(0$; 20; 30; 40; 50 e $60 \mathrm{~kg} \mathrm{ha}^{-1}$ ) aplicadas na semeadura e no final do perfilhamento.

A massa de 1.000 grãos é uma medida que apresenta forte controle genético, mas também é afetada pelas condições de temperatura e de umidade durante a fase de maturação no campo. Yano, Takahashi e Watanabe (2005) verificaram que a adubação nitrogenada em trigo realizada no emborrachamento propiciou maior massa de 1.000 grãos em relação às aplicações antecipadas. Silva et al. (2001) não constataram efeito significativo de doses e épocas de aplicação de $\mathrm{N}$ sobre o teor de proteínas das sementes de aveia-preta; observaram, entretanto, que a aplicação de $20 \mathrm{~kg} \mathrm{ha}^{-1}$ de $\mathrm{N}$ na fase de emborrachamento, promoveu aumento na massa de mil sementes. Esperava-se que a aplicação parcelada do $\mathrm{N}$ em cobertura, com parte da dose aplicada no emborrachamento, favorecesse o enchimento dos grãos, proporcionando grãos mais pesados.

A média da massa de 1.000 grãos foi significativamente maior $(30,86 \mathrm{~g})$ para o genótipo IPR 144, seguido dos genótipos CD 105, IPR 130 e IPR 136 com 27,58; 28,15 e 27,49 g que não diferiram estatisticamente (Tabela 4). Estes valores estão abaixo da média de massa de 1.000 grãos que estes genótipos normalmente apresentam (BASSOI et al., 2010), provavelmente devido à interferência dos fatores climáticos durante o período de desenvolvimento da cultura, principalmente a ocorrência de chuva próximo da época de colheita do trigo. Nos casos de grãos que germinaram antes da colheita, a diminuição do rendimento de grãos, da massa de 1.000 grãos e do peso do hectolítrico é devida à elevada taxa de respiração, a qual consome carboidratos acumulados nos grãos (BHATT et al., 1981).

Os genótipos IPR 136 e LD 052114 apresentaram menor número de espiguetas por espiga em relação aos demais. No entanto, esses apresentaram maiores valores de grãos por espigueta, juntamente com a cultivar BRS Louro, com médias de mais de dois grãos/espigueta. A produção de grãos em diferentes genótipos é função do ajuste dos componentes do rendimento: número de perfilhos por unidade, número de grãos por espiga e o peso médio de grãos. O ajuste desses componentes está diretamente ligado a um controle genético, o que leva a um ajuste entre eles dependendo do tratamento a que são submetidos.
$\mathrm{Na}$ Tabela 6 é apresentado o desdobramento da interação entre proporções da adubação nitrogenada de cobertura e genótipos de trigo para a produtividade de grãos, demonstrando que os genótipos não respondem da mesma forma ao fornecimento de N. Para os genótipos BRS Louro, IPR 130 e CD 105 as diferentes épocas de adubação nitrogenada não afetaram a característica produtividade de grãos, sendo viável uma única aplicação de $\mathrm{N}$ em cobertura, reduzindo assim o custo de uma aplicação adicional. A fertilização nitrogenada no período do perfilhamento é muito importante na determinação do número de perfilhos por planta, espigas por planta, de grãos por espiga de trigo. De acordo com Longnecker, Kirby e Robson (1993) e Mundstock e Bredemeier (2001), o $\mathrm{N}$ absorvido na fase inicial do crescimento das plantas promove o afilhamento e maior percentual de sobrevivência desses afilhos.

Os genótipos IPR 136 e LD 052114 apresentaram maiores rendimentos de grãos quando o $\mathrm{N}$ foi aplicado em uma única vez em P1 e P5, respectivamente. A adubação nitrogenada de cobertura em P1, P2 e P5 para o genótipo IPR 144 favoreceu a produtividade de grãos.

Apesar das exigências nutricionais serem menores nos estádios iniciais de crescimento, pesquisas indicam que altas concentrações de $\mathrm{N}$ na zona radicular são benéficas para promover o rápido crescimento inicial da planta e o aumento na produtividade de grãos (YAMADA, 1996).

As formas de parcelamento P3 e P4 não apresentaram diferença entre os genótipos para a produtividade de grãos. Para o parcelamento P1 a cultivar IPR 130 e a linhagem LD 052114 obtiveram menores rendimentos em comparação aos demais genótipos. Em P2 as cultivares BRS Louro e IPR 144 apresentaram maiores produtividades.

A utilização de genótipos de trigo, com alto potencial produtivo de grãos e a adubação nitrogenada são essenciais para a obtenção de alta produtividade. A produtividade de grãos é uma característica controlada por um grande número de genes, sendo, portanto, herança quantitativa. Isso ocorre porque tal produtividade depende da interação de vários componentes de rendimento (número de espiguetas e grãos, massa de 1.000 grãos e índice de fertilidade da espiga) os quais são controlados por fatores genéticos da planta e pelo ambiente (FREITAS et al., 2007). Segundo Sangoi et al. (2007), os genótipos de trigo diferem na sua capacidade de emissão de perfilhos, no seu ciclo, na arquitetura e no potencial produtivo e estas diferenças podem interferir na capacidade de absorção, 
de assimilação e de conversão de $\mathrm{N}$ para a produção de grãos. Além disso, genótipos com bases genéticas diferentes também apresentam resposta diferenciada à aplicação de $\mathrm{N}$.

A média de rendimento de grãos dos genótipos avaliados foi de 879 a $1.523 \mathrm{~kg} \mathrm{ha}^{-1}$. Estes valores estão abaixo da média de produtividade para o Estado do Paraná no ano de 2009 (1.955 kg ha-1) (COMPANHIA NACIONALDEABASTECIMENTO, 2011). De acordo com Torres et al. (2009), especificamente quanto à safra 2009, as condições de clima foram extremamente favoráveis à ocorrência da brusone, doença causada pelo fungo Pyricularia grisea que ataca as espigas podendo provocar severas reduções de rendimento.

A baixa resposta dos genótipos ao parcelamento do $\mathrm{N}$ pode ser explicada também pela ocorrência de chuva nos três dias após a aplicação de $\mathrm{N}$ realizada no perfilhamentoenoemborrachamento, quepossivelmente limitou o aproveitamento de $\mathrm{N}$ pela planta. $\mathrm{O} \mathrm{N}$ pode, em parte, perder-se tanto pelas raízes, por exsudação, por volatilização, principalmente na forma de amônia e por lixiviação (HOLTAN-HARTWIG; BOCKMAN, 1994) na forma de nitrato.

\section{CONCLUSÕES}

1. As proporções de parcelamento da adubação nitrogenada em cobertura não afetam o ciclo, o grau de acamamento, o PH, a massa de 1.000 grãos e os componentes de rendimento (número de espiguetas/ espiga, número de grãos/espigueta, número de grão/ espiga, massa de grão/espiga, número de espiga/m²) dos genótipos;

2. Para a cultivar IPR 144 a fertilização nitrogenada de cobertura em P1, P2 e P5 favorece a produtividade de grãos, sendo recomendada a adubação em P1 (perfilhamento) ou P5 (emborrachamento), evitandose assim gastos com uma aplicação adicional de N.

3. Os genótipos IPR 136 e LD 052114 apresentam maiores rendimentos de grãos quando o $\mathrm{N}$ foi aplicado uma única vez em P1 (no perfilhamento aos 20 DAE) e em P5 (no emborrachamento), respectivamente;

4. Para os genótipos BRS Louro, IPR 130 e CD 105 as diferentes épocas de adubação nitrogenada não afetam a produtividade de grãos, sendo viável uma única aplicação de $\mathrm{N}$ em cobertura no perfilhamento ou emborrachamento, reduzindo assim o custo de uma aplicação adicional.

\section{AGRADECIMENTOS}

À Coordenação de Aperfeiçoamento de Pessoa de Nível Superior (CAPES) pelo financiamento deste trabalho.

\section{REFERÊNCIAS}

ACORSSI, E. E.; FERREIRA, D. T. L. Resposta produtiva da cultura do trigo na cultivar CD 104 submetida a diferentes dosagens de adubação nitrogenada aplicada em cobertura. Cultivando o Saber, v. 2, n. 2, p. 165-173, 2009.

BASSOI, M. C. et al. Cultivares de trigo Embrapa e IAPAR. Londrina: Embrapa Soja, 2010. 30 p. (Documento, 321)

BHATT, G. M. et al. Preharvest sprouting in hard winter wheats: assessment of methods to detect genotypic and nitrogen effects and interactions. Cereal Chemistry, v. 58, n. 4 , p. 300-302, 1981.

BREDEMEIER, C.; MUNDSTOCK, C. M. Estádios fenológicos do trigo para a adubação nitrogenada em cobertura. Revista Brasileira de Ciência do Solo, v. 25, n. 2, p. 317-323, 2001.

CAViglione, J. H. et al. Cartas climáticas do Paraná. Londrina: IAPAR, 2000.

COMPANHIA NACIONAL DE ABASTECIMENTO. Acompanhamento da Safra Brasileira de Grãos 2010/2011 - Quinto levantamento, 2011. Disponível em: <http://www. conab.gov.br/OlalaCMS/uploads/arquivos/11_02_09_17_ 04_07_boletim_fevereiro-11..pdf >. Acesso em: 2 fev. 2011.

CUNHA,G.R. et al. (Org.). Indicações técnicas da Comissão Sul-Brasileira de Pesquisa de Trigo. Passo Fundo: Embrapa Trigo, 2004. $150 \mathrm{p}$.

ERNANI, P. R. Disponibilidade de nitrogênio e adubação nitrogenada para a macieira. Lages: Graphel, 2003. 76 p.

FRANCESCHI, L. et al. Fatores pré-colheita que afetam a qualidade tecnológica de trigo. Ciência Rural, v. 39, n. 4, p. 1624-1631, 2009.

FREITAS, J. G. et al. Produtividade de cultivares de arroz irrigado resultante da aplicação de doses de nitrogênio. Bragantia, v. 66, n. 2, p. 317-325, 2007

FRONZA, V.; CAMPOS, L. A. C.; RIEDE, C. R. (Org). Informações técnicas para 20008: trigo e triticale. Londrina: EMBRAPA SOJA, 2008. (Documento/Embrapa Soja, n. 301).

GUARIENTI, E. M. Qualidade industrial de trigo. Passo Fundo: EMBRAPA-CNPT, 1996. 36 p. (EMBRAPA-CNPT. Documento, 27).

GOULART, A. C. P. Perdas em trigo causadas pela brusone. In: WORKSHOP DE EPIDEMIOLOGIA DE DOENÇAS DE PLANTAS, 1., 2004, Viçosa, MG. Anais... Viçosa: Universidade Federal de Viçosa, 2004. p. 123-130. 
GOULART, A. C. P. et al. Danos em trigo causados pela infecção de Pyricularia grisea. Summa Phytopathologica, v. 33, n. 4, p. 358-363, 2007.

HOLTAN-HARTWIG, L.; BOCKMAN, O. C. Ammonia exchange between crops and air. Norwegian Journal of Agricultural Sciences, v. 14, p. 1-41, 1994.

LONGNECKER, N.; KIRBY, E. J. M.; ROBSON, A. A. Leaf emergence tiller growth and apical development of nitrogendeficient spring wheat. Crop Science, v. 33, n. 1, p. 154-160, 1993.

MEGDA, M. M. et al. Resposta de cultivares de trigo ao nitrogênio em relação às fontes e épocas de aplicação sob plantio direto e irrigação por aspersão. Ciência e Agrotecnologia, v. 33, n. 4 p. 1055-1060, 2009.

MUNDSTOCK, C. M. Planejamento e manejo integrado da lavoura de trigo. Porto Alegre: Evangraf, 1999. 227 p.

MUNDSTOCK, C. M.; BREDEMEIER, C. Disponibilidade de nitrogênio e sua relação com o afilhamento e o rendimento de grãos de aveia. Ciência Rural, v. 31, n. 2 p. 205-211, 2001.

NAKAGAWA, J.; CAVARIANI, C.; MACHADO, R. J. Adubação nitrogenada no perfilhamento da aveia-preta em duas condições de fertilidade do solo. Pesquisa agropecuária brasileira, v. 35, n. 6, p. 1071-1080, 2000.

OHLSON, O. C. et al. Teste de envelhecimento acelerado em sementes de trigo. Revista Brasileira de Sementes, v. 32, n. 4, p. 118-124, 2010.

OSÓRIO, E. A. A cultura do trigo. São Paulo: Globo, 1992. 222 p.

PERUZZO, G. Nitrogênio no seu trigo. Revista Cultivar Grandes Culturas, n.16, 2000.

ROSA, C. E. et al. (Org.). Calagem e Adubação. In: Indicações técnicas da Comissão Sul-Brasileira de Pesquisa de Trigo. Cruz Alta: FUNDACEP, 2005. cap. 2, p. 55-71.

SANGOI, L. et al. Características agronômicas de cultivares de trigo em resposta à época da adubação nitrogenada de cobertura. Ciência Rural, v. 37, n. 6, p. 1564-1570, 2007.

SANGOI, L. et al. A aplicação precoce de nitrogênio em cobertura não aumenta o rendimento de grãos do trigo cultivado na presença do alumínio. Ciência Rural, v. 38, n. 4, p. 912-920, 2008.

SCALCO, M. S. et al. Produtividade e qualidade industrial do trigo sob diferentes níveis de irrigação e adubação. Ciência e Agrotecnologia, v. 26, n. 2, p. 400-410, 2002.

SILVA, R. H. et al. Doses e épocas de aplicação de nitrogênio na produção e qualidade fisiológica de sementes de aveia preta. Revista Brasileira de Sementes, v. 23, n. 2, p. 51-55, 2001.

SILVA, J. A. G et al. Correlação de acamamento com rendimento de grãos e outros caracteres de interesse agronômico em plantas de trigo. Ciência Rural, v. 36, n. 3, p. 756-764, 2006.

SOUZA, R.S.;FERNANDES, M. S.Nitrogênio.In:FERNANDES, M. S. (Ed.). Nutrição Mineral de Plantas. Viçosa: Sociedade Brasileira de Ciência do Solo, 2006. p. 215-252.

TAZIMA, Z. H. et al. Comportamento de clones de laranja 'Valência' na região norte do Paraná. Revista Brasileira de Fruticultura, v. 30, n. 4, p. 970-974, 2008.

TEIXEIRA FILHO, M. C. M. et al. Doses, fontes e épocas de aplicação de nitrogênio em trigo irrigado em plantio direto. Pesquisa Agropecuária Brasileira, v. 45, n. 8, p. 797-804, 2010.

TORRES, G. A. M. et al. Doenças da espiga causam perda de rendimento em trigo nos estados do Paraná, São Paulo e Mato Grosso do Sul, em 2009. Passo Fundo: Embrapa Trigo, 2009. 10 p. (Embrapa Trigo. Comunicado técnico online, 255). Disponível em: <http://www.cnpt.embrapa.br/ biblio/co/p_co255.htm>. Acesso em: 5 fev. 2011.

TRINDADE, M. G. et al. Nitrogênio e água como fatores de produtividade do trigo no cerrado. Revista Brasileira de Engenharia Agrícola e Ambiental,, v. 10, n. 1, p. 24-29, 2006.

YANO, G. T.; TAKAHASHI, H. W.; WATANABE, T. S. Avaliação de fontes de nitrogênio e épocas de aplicação em cobertura para o cultivo do trigo. Semina: Ciências Agrárias, v. 26, n. 2, p. 141-148, 2005.

YAMADA, T. Adubação nitrogenada do milho. Quanto, como e quando aplicar? Piracicaba: Potafós, 1996. p. 1-5. (Informações Agronômicas, 74). 